\title{
Ocular toxicity of Anandron in patients treated for prostatic cancer
}

\author{
C HARNOIS,' M MALENFANT,' A DUPONT, ${ }^{2}$ AND F LABRIE ${ }^{2}$ \\ From the 'Departments of Ophthalmology, and ${ }^{2}$ Molecular Endocrinology and Medicine, Laval University \\ Medical Center, Quebec, Canada G1V 4G2
}

SUMMARY Approximately $65 \%$ of patients with prostatic cancer treated by the combination therapy using a gonadorelin (LHRH) agonist or orchidectomy in association with the antiandrogen Anandron complained of a delay in recovering vision after bright illumination (sun, television, bright light). Detailed ophthalmological examination revealed an increase in the photostress recovery time to an average of $9 \mathrm{~min}$, while the upper limit of normal is $1 \mathrm{~min} 20 \mathrm{~s}$. When treatment was changed from Anandron to the other pure antiandrogen flutamide, the value of the photostress recovery time markedly decreased and the visual symptoms rapidly disappeared. Since uninterrupted administration of the antiandrogen is of the outmost importance for the successful therapy of prostatic cancer, the availability of a compound such as flutamide that has no side effect other than those due to hypoandrogenicity should greatly facilitate compliance by the patients and the success of the treatment.

Antiandrogens have recently been added as part of a combination therapy with gonadorelin (LHRH) agonists or orchidectomy for the treatment of advanced prostatic cancer. ${ }^{1-3}$ This treatment is based on a more complete blockage of androgens of both testicular and adrenal origin: testicular androgens are eliminated by surgical castration or by chemical castration with an LHRH agonist, while simultaneously the action of the relatively high level of androgens of adrenal origin which remain in prostatic cancer tissue after castration is blocked in the prostatic cancer itself by a highly specific androgen antagonist or pure antiandrogen. When such complete blockage of androgens is achieved with the combination therapy, not only a greater percentage of patients show an objective response at the start of treatment but there is a much longer duration of the response and a marked improvement in survival. ${ }^{1-3}$

The only side effects observed with this treatment are related to the complete inhibition of androgens: a decrease or loss of libido in $75 \%$ of patients and hot flushes in approximately $80 \%$ of cases. However, with one antiandrogen, namely Anandron, approximately $65 \%$ of patients complained of visual symp-

Correspondence to $\mathrm{Dr} \mathrm{C}$ Harnois, Le Centre Hospitalier de l'Université Laval, 2705 Boulevard Laurier, Québec, Canada G1V 4G2. toms. The predominant visual side effect was a delay in recovering visual function after bright illumination (sun, television, bright light). This study provides an objective assessment of visual function in patients receiving the antiandrogen Anandron and the rapid recovery observed following change from Anandron to flutamide.

\section{Patients and methods}

Ophthalmic examinations were performed on 18 patients treated for prostatic cancer with the antiandrogen Anandron (5,5-dimeiniyl-3[4-nitro-3trifluoromethyl)phenyl]-24-imidazolidinedione (RU23908) at the dosage of $100 \mathrm{mg}$ every eight hours. This compound is an analogue of the pure antiandrogen flutamide (Euflex) (4'-nitro-3'trifluoromethyl-isobutyranilide). Owing to the severity of the subjective symptoms nine out of 18 patients started on Anandron were changed to flutamide at the dosage of $250 \mathrm{mg}$ every eight hours. The average age of the patients was 68.8 years.

The ophthalmic tests were corrected visual acuity, slit-lamp examination, Goldmann applanation tonometry, fundus colour photography, and photostress recovery time (PRST). This test was performed as follows: after measurement of corrected visual acuity 
(Snellen chart), one eye was illuminated for $30 \mathrm{~s}$ with a penlight held 2 to $3 \mathrm{~cm}$ from the eye. The PSRT was measured in seconds as the time required to read the Snellen letters on the line above that of best corrected visual acuity. Each eye was tested separately. Flutamide (Euflex) was supplied by Schering Canada Ltée, Montreal while Anandron was provided by Roussel Canada Ltée, Montreal.

\section{Results}

The detailed ophthalmological examination was suggested by the complaint of a delay in visual function following bright illumination in approximately $65 \%$ of patients who were receiving Anandron. This visual defect was particularly embarrassing during bright days, when vision could be delayed for several minutes when entering artificially illuminated surroundings. Exposure to the brightness of television screens was also sufficient to cause similar visual impairment in many patients. The ophthalmological examination showed no visual acuity worse than $6 / 21$ in any subject. Slit-lamp examination, applanation tonometry, and fundus examination were within normal limits in all cases. As shown in Table 1,12 of 18 patients $(67 \%)$ showed an increase in the PSRT above the normal value of $80 \mathrm{~s}$. The observed values ranged between 20 and $1500 \mathrm{~s}(25 \mathrm{~min})$, with an average of $9 \mathrm{~min}$. This delay in the PRST was observed as early as one month after

Table 1 Visual acuity and photostress recovery time in patients with prostatic cancer treated with the antiandrogen Anandron

\begin{tabular}{rllllr}
\hline Patient & $\begin{array}{l}\text { Age } \\
(y r)\end{array}$ & $\begin{array}{l}\text { Prior } \\
\text { treatment }\end{array}$ & $\begin{array}{l}\text { Treatment } \\
\text { duration } \\
\text { (months) }\end{array}$ & $\begin{array}{l}\text { Visual } \\
\text { acuity* }\end{array}$ & $\begin{array}{c}\text { PSRT } \\
\text { (seconds)* }\end{array}$ \\
\hline 1 & 71 & Orch & 1 & $6 / 6$ & 360 \\
2 & 69 & Orch & 1 & $6 / 9$ & 720 \\
3 & 69 & Orch & 2 & $6 / 7 \cdot 5$ & 180 \\
4 & 78 & None & 2 & $6 / 9$ & 183 \\
5 & 80 & None & 2 & $6 / 7 \cdot 5$ & 1500 \\
6 & 56 & Nonc & 2 & $6 / 6$ & 150 \\
7 & 71 & None & 4 & $6 / 21$ & 420 \\
8 & 75 & Tace & 4 & $6 / 12$ & 100 \\
9 & 65 & Tace & 5 & $6 / 9$ & 150 \\
10 & 74 & None & 6 & $6 / 6$ & 1260 \\
11 & 80 & None & 6 & $6 / 7 \cdot 5$ & 900 \\
12 & 71 & None & 7 & $6 / 7 \cdot 5$ & 540 \\
13 & 62 & Nonc & 1 & $6 / 9$ & 45 \\
14 & 67 & DES & 3 & $6 / 6$ & 58 \\
15 & 63 & DES & 4 & $6 / 6$ & 45 \\
16 & 62 & Orch & 4 & $6 / 6$ & 30 \\
17 & 67 & Orch & 6 & $6 / 6$ & 20 \\
18 & 58 & None & 18 & $6 / 9$ & 15 \\
\hline
\end{tabular}

Orch =orchidectomy. DES=diethylstilbestrol.

Tace $=$ chlorotrianisene.

${ }^{*}$ Results for one eye.

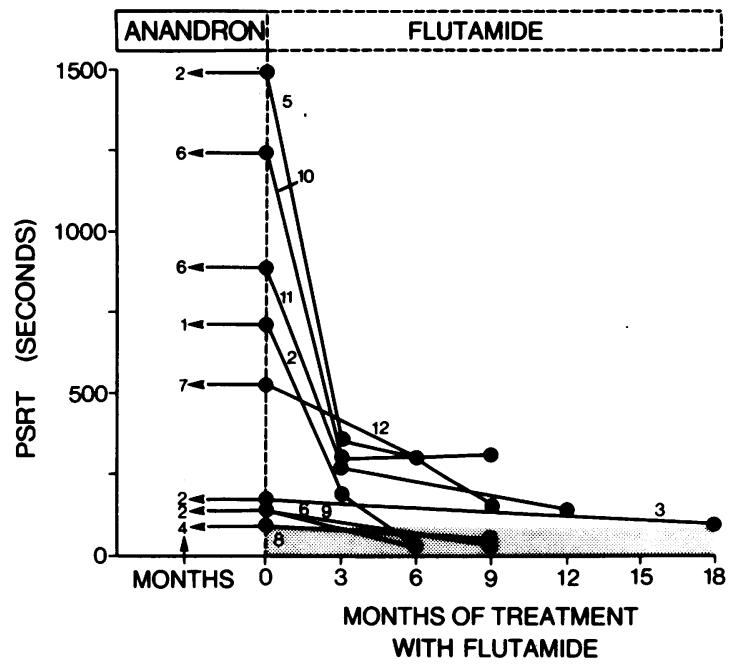

Fig. 1 Effect of changing from Anandron $(R U)$ to flutamide on the photostress recovery time (PSRT). The right-hand numbers identify the patients in Table 1 while the left-hand numbers indicate the duration of treatment with Anandron (months).

initiation of treatment and remained present for as long as the drug was given. Six patients $(33 \%)$ did not show a delay of PRST value.

Owing to the visual side effects Anandron was discontinued and replaced by flutamide in the nine patients having more severe subjective symptoms. In all cases the PSRT decreased markedly during the first time interval studied, namely three months. Some patients had been treated with Anandron for only one month, while others had received this drug for seven months. Patients who were most affected by Anandron and had a more prolonged PSRT did not show a complete recovery of the PRST value when changed to flutamide, even 12 months after discontinuation of Anandron. However, in all cases subjective symptoms disappeared within two to four weeks after changing from Anandron to flutamide.

\section{Discussion}

Compliance by the patient is a major problem which can seriously limit the efficient treatment of chronic diseases. This is especially true for the treatment of prostatic cancer, a disease affecting patients with an average age of 67 years and frequently suffering concurrent illnesses. Compliance in these patients can be easily compromised by any side effect of a drug, since it is most tempting to avoid taking the drug when the cancer is in remission and/or no pain or other symptom of the cancer is present. The consequences of a lack of compliance to the anti- 
androgen therapy is the development of autonomous tumours which will be unresponsive to any further therapy at the time of relapse. ${ }^{34}$

Visual side effects should be carefully interpreted in elderly patients. Although increased PSRT with increasing age has been reported, the value for normal individuals is no higher than $80 \mathrm{~s} .5-$

As performed, the PRST test evaluates the macular function, but it is independent of the visual acuity up to $6 / 24 .{ }^{8}$ Moreover, fundus ophthalmoscopy of the patients revealed no anatomical change of the retina. The PSRT measures the return of visual function after bleaching of the visual pigments of the photoreceptors. Therefore an increase in the PSRT value indicates a delay in regeneration of visual pigments. This can be the result of an alteration in the outer retinal segment, pigment epithelium, choriocapillaris, or the choroid. From indirect evidence it has been suggested that the photostress recovery time is dependent on the inner nuclear layer of the retina. ${ }^{9}$ This hypothesis is based on the observation that the modifications of the photostress recovery time follow those of the oscillatory potentials of the electroretinogram (ERG), which are known to originate from the inner nuclear layer. ${ }^{10}$ Despite the uncertainties about the pathophysiological basis of delayed vision, the photostress recovery time is a reliable measure of visual function, and it permits a quantitative assessment of the symptoms of delayed vision.

The present data show that approximately $65 \%$ of patients with prostatic cancer receiving Anandron as part of the combination therapy have an increase of the photostress recovery time, with values up to 25 min, the upper limit of normal being $1.2 \mathrm{~min}$. Symptoms disappeared in all the patients when
Anandron was changed to flutamide, a pure antiandrogen having no such visual side effect. Since compliance is of the outmost importance in patients with prostatic cancer, the availability of an antiandrogen having no visual side effect, such as flutamide, is of great medical importance.

\section{References}

1 Labrie F, Bélanger A, Dupont A, Emond J, Lacourcière Y, Monfette G. Combined treatment with an LHRH agonist and a pure antiandrogen in advanced carcinoma of the prostate. Lancet 1984; i: 1090.

2 Labrie F, Dupont A, Bélanger A, Lacourcière $\mathrm{Y}$, members of Laval University Prostate Cancer Program. Complete androgen blockade at start of treatment causes a dramatic improvement of survival in advanced prostate cancer. In: Labrie F, Bélanger A, Dupont A, eds. Proceedings of the international symposium on LHRH and its analogues: basic and clinical aspects. Amsterdam: Excerpta Medica, 1984: 368-79.

3 Labrie F, Dupont A, Bélanger A. Complete androgen blockade for the treatment of prostate cancer. In: De Vita VT, Hellman S, Rosenberg SA, eds. Important advances in oncology. Philadelphia: Lippincott, 1985: 193-217.

4 Resnick MI, Graynack JT. Treatment of stage IV carcinoma of the prostate. Urol Clin North Am 1975; 2: 141-61.

5 Forsius $\mathrm{H}$, Eriksson A, Krause U. The dazzling test in diseases of the retina. Acta Ophthalmol (Kbh) 1964; 42: 55-63.

6 Severin SL, Tour RL, Kershaw RH. Macular function and the photostress test. Arch Ophthalmol 1967; 77: 2-7.

7 Tiburtius HF. Der blendungstet in klinik and praxis. Graefes Arch Klin Exp Ophthalmol 1969; 178: 333-48.

8 Glaser JS, Savino PJ, Sumers KD, McDonald SA, Knighton $\mathrm{RW}$. The photostress recovery test in the clinical assessment of visual function. Am J Ophthalmol 1977; 83: 255-60.

9 Frost-Larsen K, Larsen HW, Simonsen SE. Oscillatory potentials and nyctometry in insulin-dependent diabetics. Acta Ophthalmol (Kbh) 1980; 58: 879-88.

10 Brown KT. The electroretinogram: its component and their origin. Vision Res 1968; 8: 633-48.

Accepted for publication 16 October 1985. 